\title{
Selective hydrolysis of terminal glycosidic bond in $\alpha-1$-acid glycoprotein promoted by Keggin and Wells-Dawson type heteropolyacids
}

\author{
Laura S. Van Rompuy[a], Jens Moons[a], Jo Aelbers[a], Tom Struyf[b], Wim Van den Ende[b], and Tatjana
}

N. Parac-Vogt ${ }^{\star}[a]$

\begin{abstract}
The reactivity of a range of Keggin and Wells-Dawson type heteropolyacids (HPAs): $\mathrm{H}_{3} \mathrm{PW}_{12} \mathrm{O}_{40} \mathrm{H}_{4} \mathrm{SiW}_{12} \mathrm{O}_{40}, \mathrm{H}_{3} \mathrm{PMo}_{12} \mathrm{O}_{40}, \mathrm{~K}_{6} \mathrm{P}_{2} \mathrm{~W}_{18} \mathrm{O}_{62}$, and $\mathrm{NaH}_{2} \mathrm{~W}_{12} \mathrm{O}_{4}$, towards the heavily glycosylated $\alpha$-1-acid glycoprotein (AGP) is reported. Sodium dodecyl sulfate polyacrylamide gel electrophoresis (SDSPAGE) and high-performance anion exchange chromatography with pulsed amperometric detection (HPAEC-PAD) show that after incubation of the protein with HPAs at $80^{\circ} \mathrm{C}$ and $\mathrm{pH} 2.8$ complete hydrolysis of terminal glycosidic bond has been achieved, resulting in the removal of sialic acids with no observed destruction of the protein core or the residual glycan chains. The ${ }_{1} \mathrm{H}$ NMR spectroscopy confirmed that the released sialic acids preserve intact structure upon their excision from the protein, which makes the reported method suitable for the analysis of sialic acid modifications which play an important role in numerous biological processes. The presence of other sugars was not detected by ${ }_{1} \mathrm{H}$ NMR and HPAEC-PAD, suggesting that HPAs hydrolyze only the terminal glycosidic bond in the glycoprotein, resulting in the selective release of sialic acid from AGP. The kinetic results have shown that under equal temperature and $\mathrm{pH}$ conditions, the hydrolysis of the terminal glucosidic bond occurred faster in the presence of HPAs compared to conventional mineral acids. The observed rate constants were in the range 6,7 x 10-2 -11,9 $\times 10-2$ min-1 and the complete and selective excision of sialic acids could be achieved within $60 \mathrm{~min}$ of incubation. The Trp fluorescence and CD spectroscopy show that non-covalent interaction between HPA and protein takes place in solution which could lead to stabilization of the sialosyl cation that is formed during the glycosidic bond hydrolysis by anionic HPA cluster.
\end{abstract}

\section{Introduction}

Sialic acids (SIAs) refer to a family of 9-C carboxylated monosaccharides which frequently occupy the terminal position on glycan chains found in glycoconjugates such as glycoproteins, glycolipids and lipopolysaccharides.[1] Four major types of SIAs are defined, based on the substituent on $\mathrm{C}-5$ atom: i) an amino group in neuraminic acid (Neu), ii) an acetamido group in $\mathrm{N}$ acetylneuraminic acid (Neu5Ac) (Figure 1A), iii) a glycolylamido group in N-glycolylneuraminic acid (Neu5Gc) (Figure 1B) and iv) a hydroxyl group in ketodeoxy-nonulosonic acid (KDN). However, a wider variety of derivatives is possible through substituents present on carbons $4,7,8$, and 9 .

[a] Department of Chemistry

KU Leuven

Celestijnenlaan 200F, 3001, Leuven, Belgium

E-mail: tatjana.vogt@kuleuven.be

[b] Department of Biology, Molecular Plant Biology KU Leuven

Kasteelpark Arenberg 31, B-3001 Leuven, Belgium
A

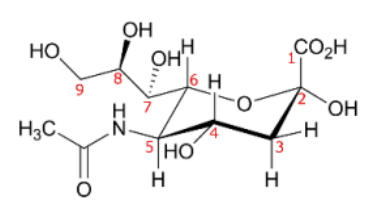

B

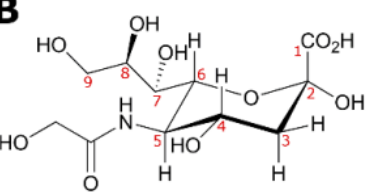

$\mathrm{N}$-acetylneuraminic acid (Neu5AC)

$\mathrm{N}$-glycolylneuraminic acid (Neu5Gc)

Figure 1. The two most commonly occurring SIAs: N-acetylneuraminic acid (A) and N-glycolylneuraminic acid (B).

The terminal position of SIAs in glycoconjugates and their negative charge ( $\mathrm{pK}_{\mathrm{a}}=2.2$ for the $\mathrm{C} 1$ carboxyl group) are essential factors for their numerous biological functions [2] where they mediate a variety of cell-cell and cell-matrix processes.[1] They also affect many cell surface features and act as ligands in receptor-mediated intercellular interactions, host cell-pathogen recognition progresses and lymphocyte-endothelial cell interactions.[3]

Modifications of the general SIA structure play an important role in these processes, but they are difficult to examine due to the low stability of SIA under isolation and purification reaction conditions, and sample contamination with esterase enzymes.[4] SIA metabolic changes show potential as disease biomarkers as they have been detected for a wide variety of diseases, and monitoring of SIA levels is also crucial in the development of therapeutic proteins, which was the most significant and fastest growing segment of the pharmaceutical market in the past decade.[5] SIAs, also have a major impact on receptor recognition[6] and biological half-life $[7]$ of therapeutics, and monitoring of the degree of sialylation is therefore a crucial step in the manufacturing process of these products, as insufficient or inconsistent sialylation greatly affect their quality.[8]

A common step in monitoring SIA levels in both biomarker applications and the quality assessment of glycoprotein pharmaceuticals, is the release of SIA from the sample by glycosidic hydrolysis. Currently two alternative approaches based on enzymatic release or acid hydrolysis are available to achieve this. Enzymatic release employs neuraminidases or sialidases which hydrolyze the bond between the terminal SIA and the adjacent sugar under mild reaction conditions. However, the specificity of the enzymes is dependent on O-acetylation, the occurrence of $\mathrm{N}$-glycolyl groups and the type of glycosidic linkage and is limited to terminal SIA. Therefore, the low-cost acid hydrolysis is more commonly employed. This procedure involves the release of SIA by using $25-100 \mathrm{mM}$ of mineral acids or $2 \mathrm{M}$ solutions of trifluoroacetic acid (TFA) and acetic acid, typically at 
$80{ }^{\circ} \mathrm{C}$.[1a, 9] These procedures are not affected by sample composition, but the acidic conditions and high temperature often lead to partial destruction of the protein and also of SIA. Additionally, information on the type of glycosidic link of sialic acids to the glycan chains cannot be retained using acid hydrolysis.[1a] Therefore, the main challenge in the development of new hydrolytic procedures is maximizing the release of SIAs, while minimizing the generation of hydrolytic products. [1a, 10] Polyoxometalates (POMs) constitute a large class of nanosized metal-oxygen cluster anions used in a wide variety of applications. [11] Heteropolyacids (HPAs) are a subclass of POMs, which have protons as counter-cations, and due to their strong Brønsted acidity they have been extensively used in catalysis.[12] Two common HPAs structures are the Keggin structure $\left[\mathrm{XM}_{12} \mathrm{O}_{40}\right]_{n-}$ and its derivative Wells-Dawson $\left[\mathrm{X}_{2} \mathrm{M}_{18} \mathrm{O}_{62}\right] \mathrm{n}$-, with $\mathrm{X}$ the heteroatom (most commonly are $\mathrm{P}_{5_{+}}, \mathrm{Si}_{4_{+}}$, or $\mathrm{B}_{3+}$ ), and $\mathrm{M}$ the addenda atom (commonly $\mathrm{Mo6}_{+}$or $\mathrm{W}_{6+}$ ) (Figure 2).[12-13] HPAs can catalyze a wide variety of reactions in homogeneous liquid phase, where they typically show higher catalytic activities than mineral acids. The reactions can therefore be carried out at lower acid concentrations or temperatures.[14] An additional advantage of HPAs is the lack of side reactions, such as sulfonation, chlorination and nitration, and their safety and ease of handling.[12, 15]
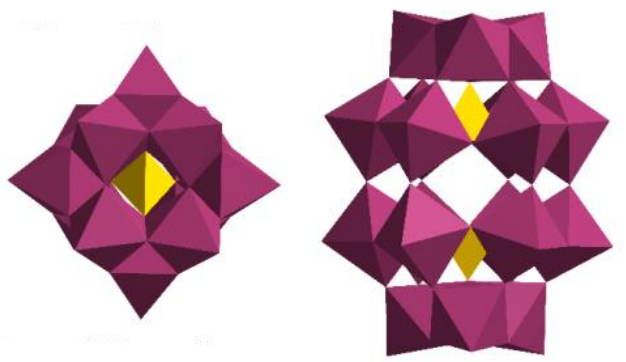

Figure 2. Left: representation of Keggin structure $\left(\left[\mathrm{XM}_{12} \mathrm{O}_{40}\right]_{\mathrm{n}}\right)$ of phosphotungstic acid, silicotungstic acid and phosphomolybdic acid. Right: Representation of Wells-Dawson structure ( $\left.\left[\mathrm{X}_{2} \mathrm{M}_{18} \mathrm{O}_{62}\right] \mathrm{n}-\right)$. The central yellow tetrahedral contain the heteroatoms $\left(\mathrm{P}_{5+}\right.$ or $\left.\mathrm{Si}_{4+}\right)$ surrounded by oxygen atoms. The surrounding magenta octahedra contain the addenda atoms (Mo6+ or $\mathrm{W}_{6+}$ ) surrounded by oxygens.

In addition to the wide range of organic transformations, POMs have been recently emerging as catalysts for the biologically relevant substrates. Phosphotungstic acid (PTA) were employed for the hydrolysis of cellulose to glucose, where a high yield and selectivity were achieved, which was attributed to PTAs high thermal stability and strong Brøndsted acidity.[16] We have previously shown that POMs can efficiently hydrolyze biologically relevant bonds such as phosphoester[17] and peptide bonds[18] found in RNA, DNA and proteins. Recently, we also demonstrated that HPAs can be used as catalysts for the hydrolysis of glycosidic bonds in glycoproteins. In the presence of PTA selective hydrolysis of the penultimate glycosidic bond was achieved in fetuin, which was used as a model glycoprotein, resulting in release of SIA after incubation at $37^{\circ} \mathrm{C}$ and $\mathrm{pH} 2.8$. These initial results demonstrated that HPAs have potential to act as a promising alternative to conventional acids in the search for a procedure that maximizes SIA release, while minimizing degradation.[19] Therefore in this manuscript, a range of HPAs have been investigated for the selective release of SIAs from alpha 1-acid glycoprotein (AGP, orosomucoid), a glycoprotein with high glycan content. AGP is commonly used as a model protein in SIA and glycosylation studies because of its known structure and its high SIA and glycan content. It is a major acute phase protein of which the serum concentration is raised in reaction to systemic tissue injury, inflammation and infection.[20] In addition to the detailed kinetic and interactions studies between HPAs and the protein, high performance anion exchange chromatography with pulsed amperometric detection (HPAECPAD) was used to quantify the amount of SIAs resulting from the controlled hydrolysis of the terminal glyosidic bond in AGP.

\section{Results and Discussion}

\section{SIA release from AGP promoted by heteropolyacids}

AGP is a heavily glycosylated protein with a molecular weight that varies between 37-54 kDa, depending on the level of glycosylation. It has a low pl of approximately 2.8-3.8 and consists of a single polypeptide chain of approximately $200 \mathrm{AA}$, depending on the species.[21] Different species carry a different number of $\mathrm{N}$ linked glycans, which make up approximately $45 \%$ of the molar mass of the protein. Bovine AGP, which was used in this study, contains mainly diantennary oligosaccharides terminated by $\mathrm{N}$ acetylneuraminic acid and N-glycolylneuraminic acid.[22] Its biological function is not yet fully understood but a number of its activities are known, e.g. AGP can act as a drug carrier and immune modulator.

On SDS-PAGE gels, bovine AGP has a double band structure due to heterogeneous glycosylation with a more intense band at higher Mw (A in

) and a less intense band at slightly lower Mw (B in

). Because of its high glycosylation content, SIA release can be conveniently followed as a reduction in molecular weight on SDSPAGE gels.

AGP $(0.2 \mathrm{mg} / \mathrm{mL})$ was incubated in presence of different HPAs and metatungstate $(0.4 \mathrm{mM}$ ) (Figure 2), hydrochloric and sulphuric acid, which are commonly used for SIA release. All samples were adjusted to equal $\mathrm{pH}(2.8 \pm 0.1)$ and incubated at $80^{\circ} \mathrm{C}$. For each sample, an SDS-PAGE gel was run after a certain time increment, and the molecular weight of AGP was determined by using Image Lab (Bio-Rad). Both AGP bands showed a similar decrease in molecular weight upon incubation with acids. The $\mathrm{Mw}$ of the band $\mathrm{A}$ at $52 \mathrm{kDa}$, representing the fully sialylated AGP, decreased to $46.5 \mathrm{kDa}$ after $2 \mathrm{~h}$, representing a weight loss of $11 \%$. This is within the range that is expected for a loss of approximately $15 \mathrm{SIAs}$ that are present in AGP. The Mw of band $B$ was also decreased from $46.5 \mathrm{kDa}$ to $42.3 \mathrm{kDa}$, and for both $A$ and $B$ bands the plateau was reached in ca. $30 \mathrm{~min}$. As double band structure of the protein in the SDS-PAGE gel originates from different glycoforms present in the sample, a combined decrease in $\mathrm{Mw}$ and double band retainment suggests that only SIA is released without degradation of the rest of the glycan chains. It is important to note that SDS-PAGE gels did not show any additional protein fragments which would indicate protein degradation during the incubation process. 


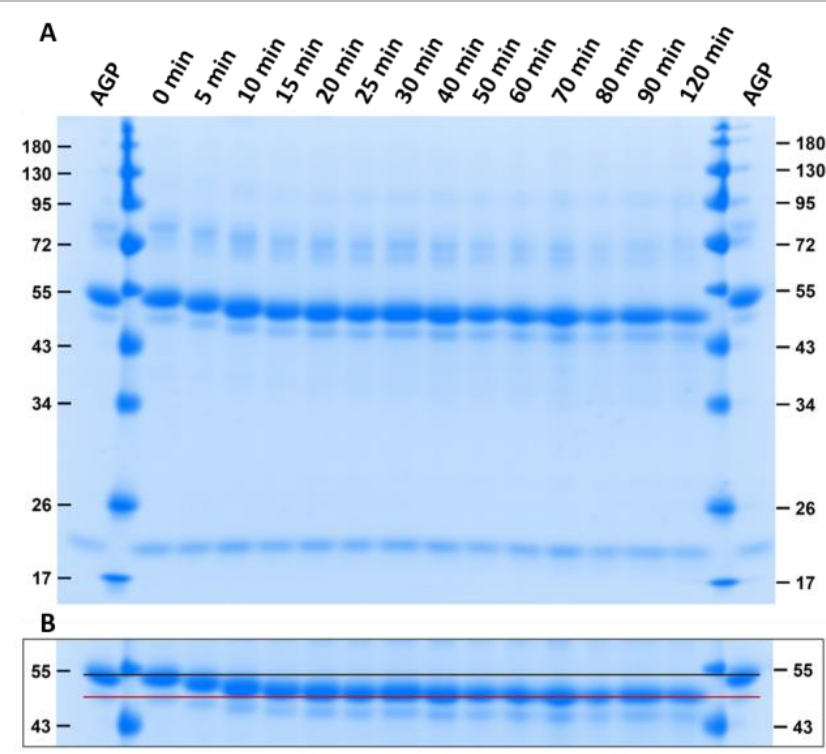

Figure 3. a) SDS-PAGE gel and decrease of AGP Mw over time upon incubation in $\mathrm{H}_{2} \mathrm{O}$ at $\mathrm{pH} 2.8$ and $80{ }^{\circ} \mathrm{C}$ for 2 hours in presence of $\mathrm{H}_{4} \mathrm{SiW}_{12} \mathrm{O}_{40}$ $(0.4 \mathrm{mM})$. The faint bands at higher $\mathrm{Mw}(\mathrm{ca} 72 \mathrm{KDa})$ are likely oligomers of AGP present in the sample while the band at ca $20 \mathrm{KDa}$ originates from bromopheno blue in the sample buffer which is used to follow the run of the gel. b) The enlargement of the gel clearly shows the decrease in Mw of both proteins bands over time.

The decrease of $\mathrm{Mw}$ of the main fetuin band $(\mathrm{A})$ was plotted as function of the time (Figure 4 and Figures $S$ 1-7), and the data were fitted using the exponential decay to determine the rate constant (Table 1). The kinetic results (Figure 4 and Table 1) show that all tested HPAs release SIA faster than the mineral acids. A similar rate increase was also observed for the isopolyacid metatungstate $\left(\mathrm{NaH}_{2} \mathrm{~W}_{12} \mathrm{O}_{40}\right)$, a POM without a heteroatom that adopts a quasi Keggin-structure. Due to the faster hydrolysis by HPAs, SIA release was completed before protein degradation occurred, which was not the case for the AGP incubation with mineral acids where additional protein bands were observed, indicating protein degradation. As expected, under the same $\mathrm{pH}$ conditions no significant difference was seen for the acid and salt form of phosphotungstic acid as HPA salts with small counter-cations fully dissociate in solution like their acidic counterparts.[12]

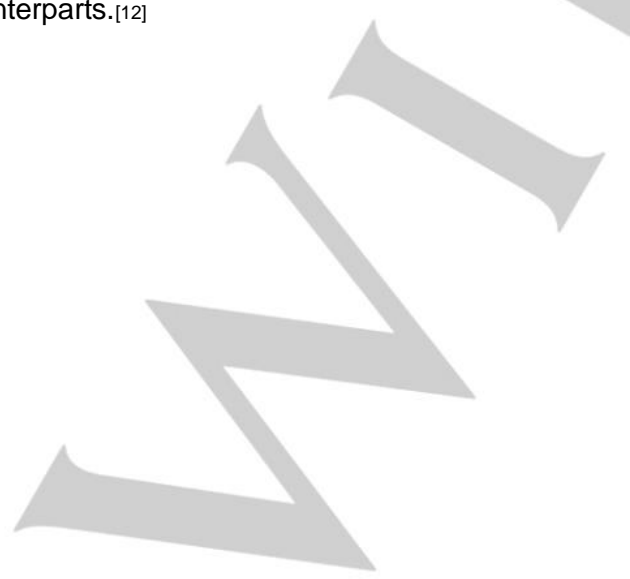

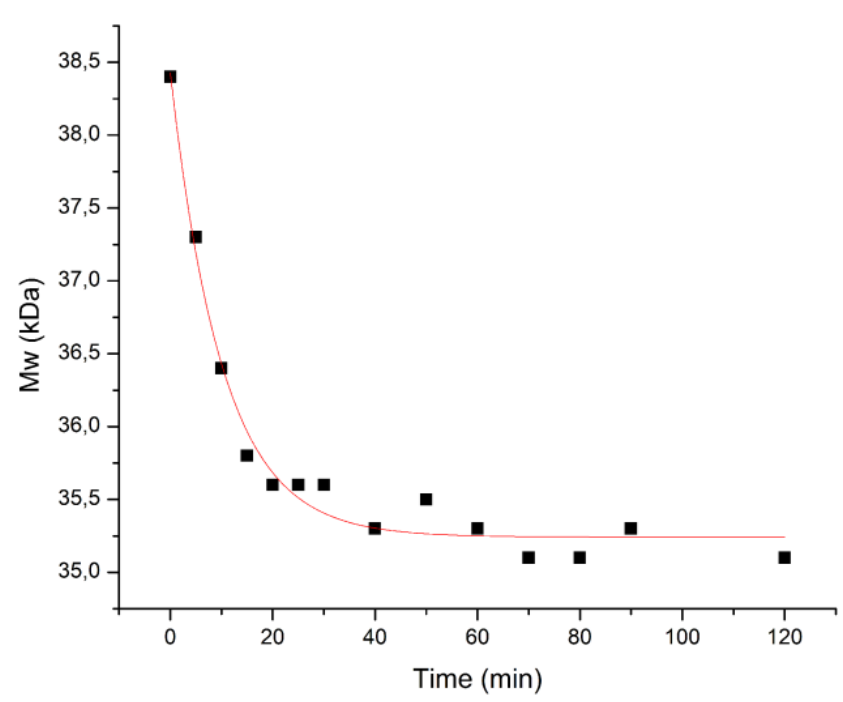

Figure 4. Plot of the decreasing $\mathrm{Mw}$ of $\mathrm{AGP}$ over time upon incubation in $\mathrm{H}_{2} \mathrm{O}$ at $\mathrm{pH} 2.8$ and $80{ }^{\circ} \mathrm{C}$ for 2 hours in presence of $\mathrm{H}_{4} \mathrm{SiW}_{12} \mathrm{O}_{40}(0.4 \mathrm{mM})$. An exponential decay was fitted to the data to determine the rate constant.

Interestingly, all tested POMs exhibited activity towards release of SIA from AGP, despite their different structures and properties. Keggin type HPAs have different stabilities in solution depending on their composition, resulting in the presence of different structures in solution depending on the $\mathrm{pH}$ and other solution properties, e.g. POM concentration and ionic strength if the solution.[12] At pH 2.8, the most stable HPA, silicotungstic acid, and the isopolyacid metatungstate are still largely present as the intact Keggin monomer.[23] Phosphotungstic acid, with intermediate stability, is likely largely present as a mixture of different species that contain two phosphorus heteroatoms and have structures similar to the Wells-Dawson HPA.[24] The least stable HPA, phosphomolybdic acid, most likely exists as the lacunary Keggin form, $\mathrm{PMO}_{11} \mathrm{O}_{397-.[25]}$ These results suggest that the exact size, charge and shape of the POM anion scaffold have no major influence on the reactivity. It also appears that the heteroatom does not influence the reactivity, as metatungstate, an isopolyanion with two protons instead of a heteroatom in the center of the Keggin structure, exhibited the same reactivity as its HPAs Keggin counterparts, PTA and STA. AGP was also incubated in presence of $\mathrm{Na}_{2} \mathrm{WO}_{4}$, the final breakdown product of the tungstate polyacids. However, the SDS-PAGE gels showed that upon addition of sodium metatungstate most of AGP was no longer present in the solution and a white precipitate was observed in the Eppendorf tube. It has been previously shown that under similar conditions, $\mathrm{Na}_{2} \mathrm{WO}_{4}$ can cause aggregation of proteins via electrostatic interactions resulting in their precipitation from solution.[26]

AGP $(0.2 \mathrm{mg} / \mathrm{mL})$ was also incubated with different concentrations of PTA $(0.08-0.80 \mathrm{mM})$. Figure $S 8$ shows that no significant difference in hydrolysis of AGP was observed when different concentrations of PTA were used (0.08-0.80 mM). Even at the lowest PTA concentration $(0.08 \mathrm{mM})$, HPA remains in excess of AGP (approximately $4.8 \mu \mathrm{M}$ ). Bovine AGP has five possible glycosylation sites and was found to carry mainly di- and tri-sialylated diantennary glycan chains.[27] Each AGP molecule 
therefore carries approximately 10 to 15 SIAs. At $0.08 \mathrm{mM}$ PTA, the ratio of SIA to PTA therefore approaches 1:1, indicating that a large excess of PTA is not required.

\section{SIA release followed by NMR}

${ }_{1} \mathrm{H}$ NMR spectroscopy has been previously used to follow SIA release from AGP with neuraminidase enzyme in real-time.[28] The release of SIA from the large AGP molecule, can be detected in the ${ }_{1} \mathrm{H}$ NMR spectrum via occurrence of a sharp set of peaks. When bound to AGP the SIA peaks are broad due to the overall slow tumbling of the protein, however upon hydrolysis SIA adopts sharp NMR peaks characteristic of low molecular weight molecules.[29]

Table 1. Observed rate constants of SIA release in presence of various acids and $\mathrm{POMs}$ at $\mathrm{pH}=2,8$ and $80^{\circ} \mathrm{C}$.

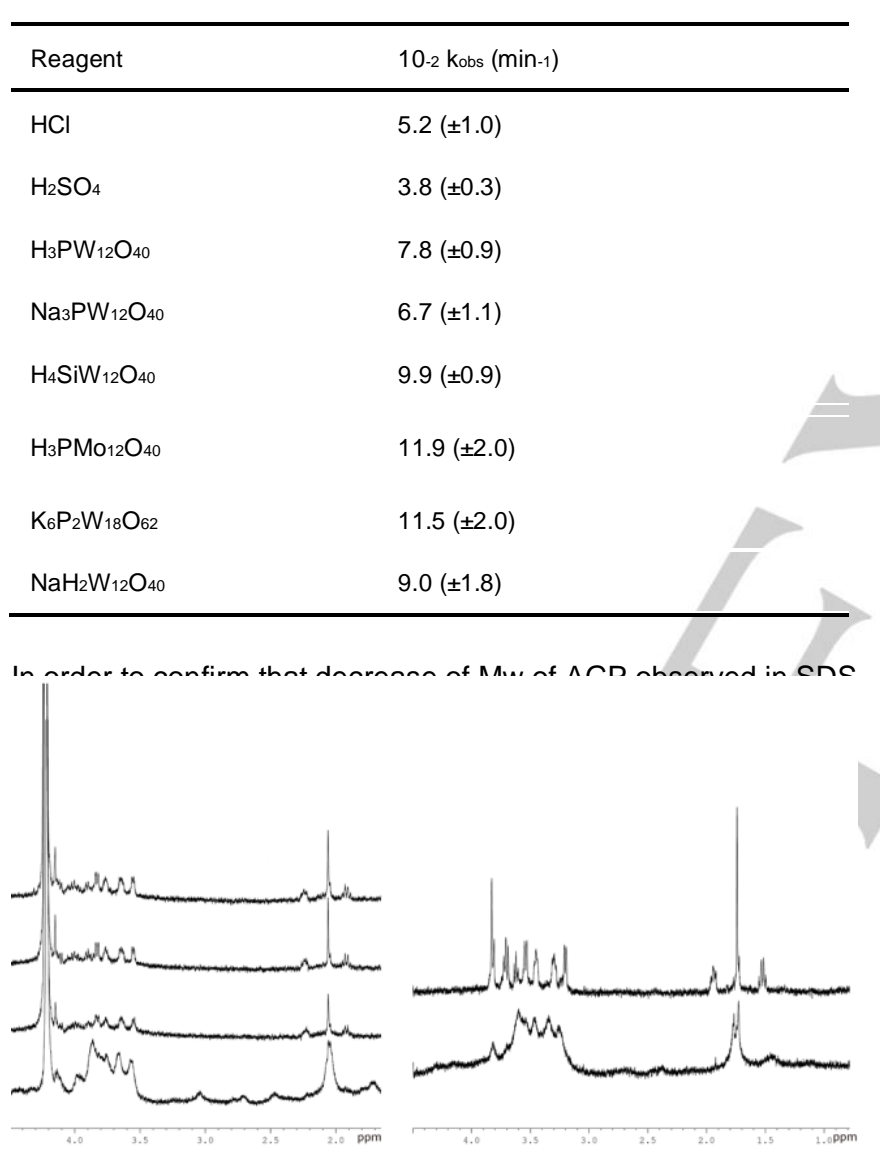

Figure 5). Signals belonging to both SIAs are observed in the region between 3.1-3.5 ppm, $(\mathrm{H} 5-\mathrm{H} 9)$, and at $2.76 \mathrm{ppm}(\alpha-\mathrm{H} 3$ eq $)$, $2.26 \mathrm{ppm}\left(\beta-\mathrm{H}_{\mathrm{eq}}\right), 1.84 \mathrm{ppm}\left(\beta-\mathrm{H}_{\mathrm{ax}}\right)$ and $1.65 \mathrm{ppm}(\alpha-\mathrm{H} 3 \mathrm{ax})$. Signals specific to Neu5Ac and Neu5Gc can be seen at $2.05 \mathrm{ppm}$ $(5 \mathrm{Ac})$ and $4.14 \mathrm{ppm}(5 \mathrm{Gc})$ respectively. The presence of $\beta$ anomer signals is further indication that SIA is released, as the sugar is bound in a-conformation and largely converts to the more stable $\beta$-form in solution.[30] No other well-resolved signals, indicating the presence of other sugars, were observed in the ${ }_{1} \mathrm{H}$ NMR spectrum, suggesting that only SIAs were selectively released during the incubation.

In order to address the stability of acid labile residues under the reported protocol the hydrolysis of the phosphate bond in glucose- 6-phosphate as a model substrate has been examined. As shown in Figures S 9 and S 10 in the SI, no hydrolysis of the phosphate bond was observed in ${ }_{1} \mathrm{H}$ and ${ }_{31} \mathrm{P}$ NMR spectra when glucose-6phosphate was incubated with $0.05 \mathrm{mM} \mathrm{STA}(\mathrm{pH} 2.8)$ for 2 hours at $80^{\circ} \mathrm{C}$. The data also indicate that the overall glucose structure remains intact and that stability of the C6-phosphate group is preserved.
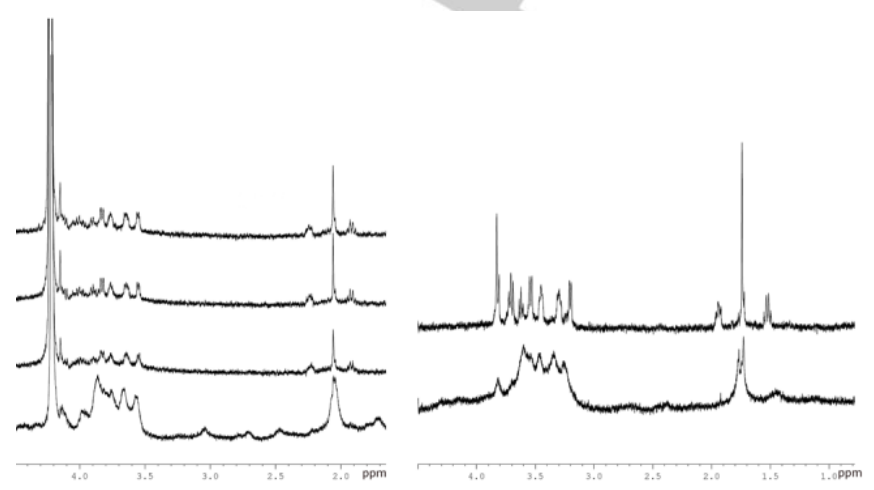

Figure 5. Left: ${ }_{1} \mathrm{H}$ NMR spectra of AGP $(0.1 \mathrm{mM})$ during incubation with STA $(0.5 \mathrm{mM})$ at $80^{\circ} \mathrm{C}$ and $\mathrm{pD} 2.8$; spectra were recorded after (from bottom to top): $0 \mathrm{~min}, 25 \mathrm{~min}, 50 \mathrm{~min}$, and $75 \mathrm{~min}$. Right: ${ }_{1} \mathrm{H}$ NMR spectra taken before and after incubation for $2 \mathrm{~h}$. The spectra were recorded at $10^{\circ} \mathrm{C}$ to improve spectral resolution.

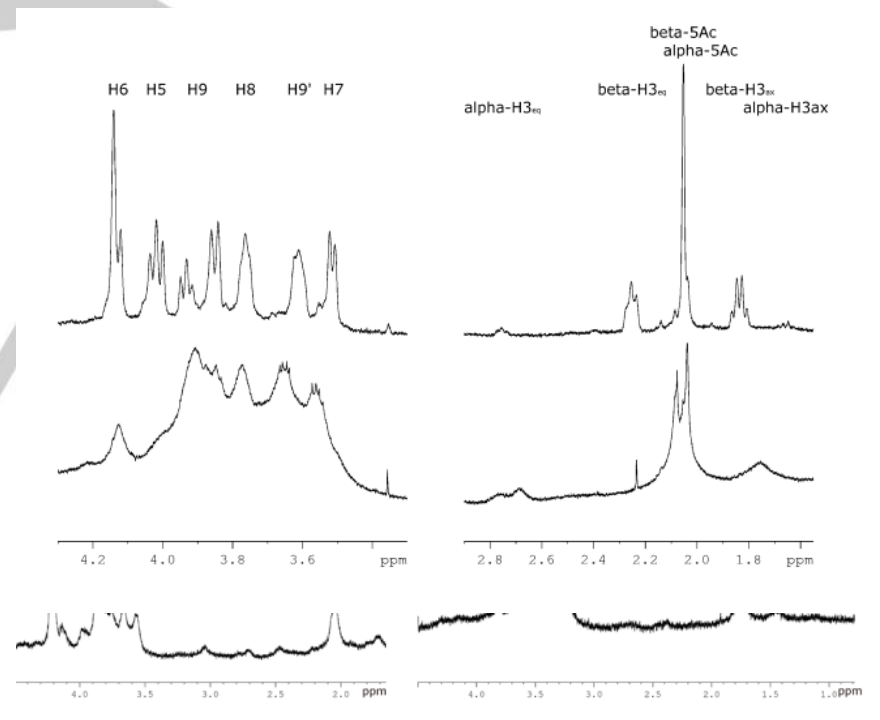

Figure $\mathbf{5}$. The spectrum at the bottom was recorded immediately after mixing and the spectrum at the top after 2 hours of incubation. After incubation the bulk region on the left shows the $5 \mathrm{Gc}$ (N-glycolylneuraminic acid) and $\mathrm{H} 5-\mathrm{H} 9$ signals emerging while on the right, the $\mathrm{H} 3$ and $5 \mathrm{Ac}$ ( $\mathrm{N}$-acetylneuraminic acid) are clearly detected.

\section{Interaction between AGP and PTA studied by tryptophan fluorescence and circular dichroism (CD) spectroscopy}

The interaction between AGP and PTA was studied by tryptophan (Trp) fluorescence spectroscopy, which is very sensitive to local changes in protein conformations that are caused by binding of 
WILEY-VCH

external ligands. The ability of POMs to interact with proteins has been well documented,[31] and may be best reflected in the POMs ability to facilitate crystallization of the small ribosomal subunit.[32] Bovine AGP carries three Trp residues and it has homologous structure with human AGP. The latter has been structurally characterized by single crystal $\mathrm{x}$-ray crystallography, which reveals that all three Trp residues are located at the surface of the protein.[33] According to the protein contact potential, these residues are located in largely negatively charged surface areas of the protein with potential glycosylation sites in relative proximity (Error! Reference source not found.). However, under the low $\mathrm{pH}$ conditions of the experiment $(\mathrm{pH}=2.8)$, the protein is likely to be partially unfolded and more positively charged, which may facilitate interaction between AGP and negatively charged PTA.
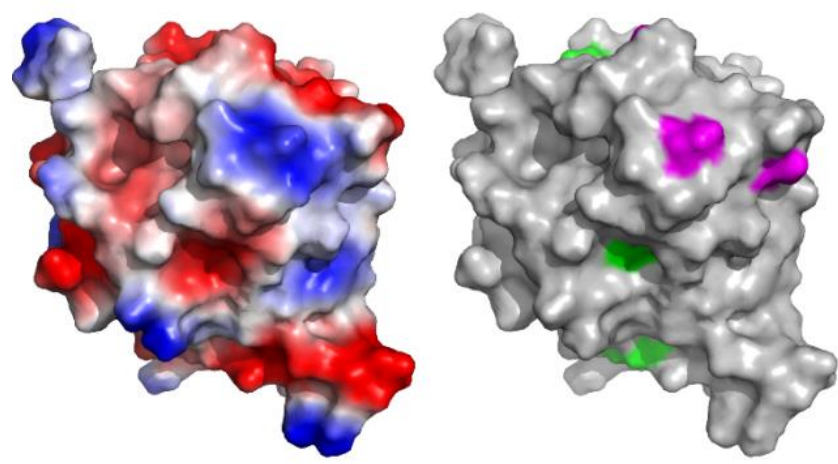

Figure 7. Crystal structure of human AGP. Left: surface representation with protein contact potential; positive patches are represented in blue, negative patches in red. Right: surface representation with Trp residues represented in green. Potential glycosylation sites are represented in magenta.

Trp fluorescence spectra of AGP show increasing quenching of fluorescence with increasing PTA concentration, indicating that binding takes place in solution. Previous work has shown that POMs generally interact with proteins through static quenching, where a ground state complex is formed between the POM and protein, and not by dynamic quenching, where the excited state of the molecule is deactivated by a non-interactive collision. $[18 b, \mathrm{j}$, 34] The linear relationship between the $F_{0} / F$ and the PTA concentration suggests that the quenching of Trp fluorescence is due to the static quenching and formation of ground state complex between AGP and PTA (Figure S 11).

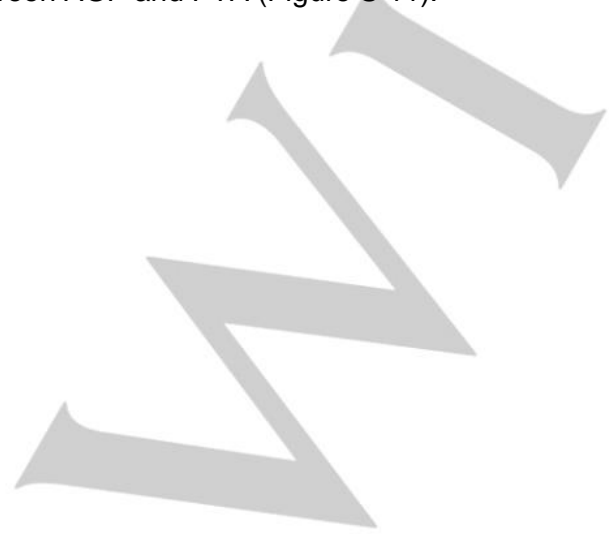

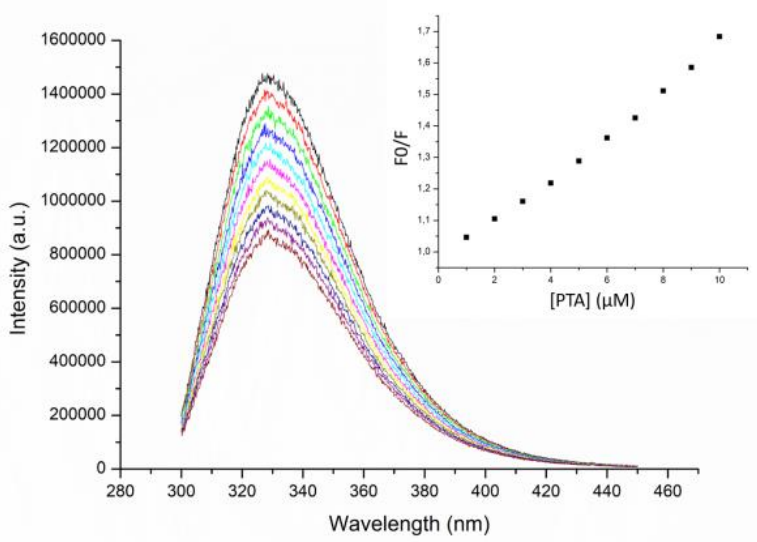

Figure 8. Spectra of the tryptophan emission of AGP $(10 \mu \mathrm{M})$ in citrate buffer $(\mathrm{pH} 2.8)$ with increasing PTA concentration $(0-10 \mu \mathrm{M})$. The fluorescence decreases upon increasing the PTA concentration. The insert shows a plot of the derived Stern-Volmer equation used to derive the association constant.

A derived Stern-Volmer equation was used to correlate the fluorescence quenching with the binding strength between AGP and PTA (Equation 1).

\section{Equation 1}

$$
\log \frac{F_{0}-F}{F}=\log \mathrm{K}_{\mathrm{a}}+\mathrm{n} \log [\mathrm{Q}]
$$

The equation derives the association constant $\left(\mathrm{K}_{\mathrm{a}}\right)$ and number of quencher molecules $(n)$ from the measured fluorescence in each step $(F)$ and the fluorescence in absence of quencher $(F)$ and the concentration of the quencher ([Q]). An association constant of $4.0 \times 10-5 \mathrm{M}-1$ and a value of 1.2 for the number of PTA bound molecules per complex were obtained from fitting the data to Equation 1 (Figure 8). The Trp fluorescence quenching data indicate that negatively charged SIAs, terminating most of the glycan chains, do not prevent the interaction between negatively charged HPA and AGP.

The effect of PTA on the structure of AGP was further studied by CD spectroscopy. Although that HPAs are not optically active chiral molecules and therefore do not show a CD spectrum, their UV absorbance overlaps strongly with the UV range typically used for secondary structure determination of proteins $(240 \mathrm{~nm}$ and below). For this reason, a low concentrations of PTA $(0.08 \mathrm{mM})$ was employed as high concentrations may induce artefacts in the UV region of the CD spectra. AGP $(0.2 \mathrm{mg} / \mathrm{mL})$ was dissolved in an aqueous solution of PTA $(0.08 \mathrm{mM})$ and the $\mathrm{pH}$ of the mixture was adjusted to 2.8. The sample was compared to two control samples: i) AGP dissolved in a dilute solution of $\mathrm{HCl}$ at $\mathrm{pH} 2.8$ and ii) AGP dissolved in water $(\mathrm{pH}=5.1)$. 


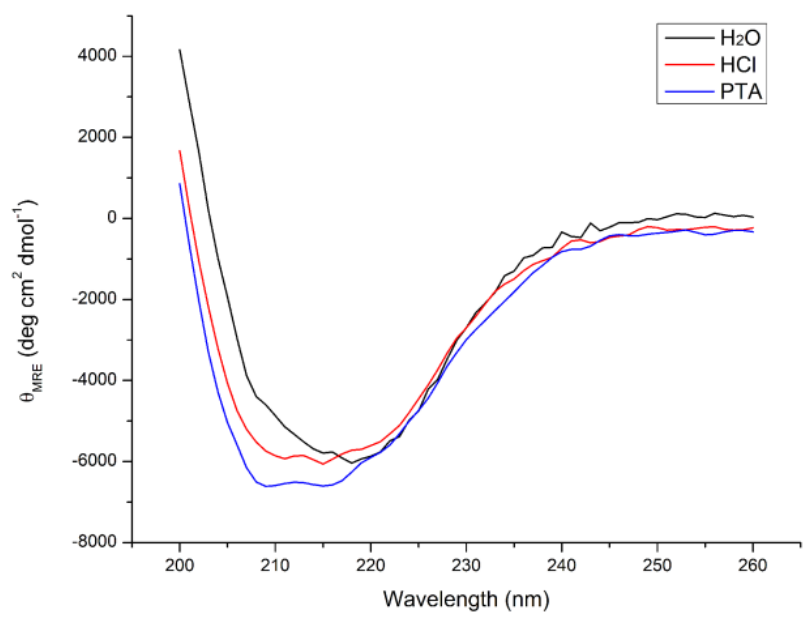

Figure 9. Circular dichroism spectra of AGP dissolved in an aqueous solution of $A G P(0.08 \mathrm{mM}$, red) and a dilute solution of $\mathrm{HCl}$ (black) at $\mathrm{pH} 2.8$.

The spectra (Figure 9) show that in presence of PTA, the secondary structure of AGP is slightly modified. The $\alpha$-helix and $\beta$-strand content was estimated with K2D3[35] software, which indicated an increase in $\alpha$-helix content (15\% vs $9 \%$ ) and a slight decrease in $\beta$-strand content ( $30 \%$ vs $33 \%$ ) in presence of PTA. Acidification of the sample from $\mathrm{pH} 5.1$ to 2.8 with $\mathrm{HCl}$ only slightly decreased the $\beta$-strand content from $36 \%$ to $33 \%$, while the $\alpha$ helical content remained stable at $9 \%$. These values are indicative and should be interpreted with caution, however, the main conclusion is that PTA induces slight changes in the secondary structure of AGP which indicates that interaction between PTA and AGP takes place in solution.

\section{Analysis of SIA by HPAEC-PAD}

HPAEC-PAD is an established technique for the analysis and quantification of both SIAs and neutral sugars of glycoproteins. The technique separates mono- or oligosaccharides on an anionexchange column with a high $\mathrm{pH}(>12)$ stationary phase which turns the neutral monosaccharides into oxoanions. The separated sugars are then detected by PAD, a direct detection technique that does not require labeling of the sugars prior to analysis, unlike the commonly used alternative HPLC with UV detection.[36] Because of the ease and high sensitivity of the method, we opted to develop a protocol for SIA analysis of glycoproteins with HPA induced release. PTA was our HPA of choice as is it the cheapest HPA available and often already present in biochemical labs, as it is widely used as an electron microscopy stain.[37] Measurements were performed by simply injecting the samples, which were prepared in the same way as the samples for the SDS-PAGE analysis, without prior purification. Fouling of the column by the HPA, a possible concern, was not observed. Indeed, under the conditions $-90 \mathrm{mM} \mathrm{NaOH}$ - PTA breaks down to its constituents $\mathrm{PO}_{43}$ - and $\mathrm{WO}_{42-.[24]}$ Samples were analyzed after $0,30,60,120$ and 180 min incubation at $80^{\circ} \mathrm{C}$ and $\mathrm{pH} 2.8$ and compared to $\mathrm{HCl}$. The results clearly demonstrate that the presence of PTA greatly increases the SIA release rate when compared to the control $\mathrm{HCl}$ (Figure 10). In presence of PTA, the highest measured values for both $\mathrm{N}$-acetylneuraminic acid and $\mathrm{N}$ - glycolylneuraminic acid were obtained after $60 \mathrm{~min}$. At 120 and $180 \mathrm{~min}$, the values decreased, indicating that SIA breakdown may occur under prolonged incubation. The results also showed that in the control samples with $\mathrm{HCl}$, the SIA release was not complete after 180 min incubation, and that at this point the measured SIA levels are still lower than those measured after 30 min incubation with PTA. Samples were also checked for the release of other neutral monosaccharides from the glycans, however their presence was not detected (Figure $S 12$ ). It should be noted that our experimental conditions (0.4 mM PTA, pH 2.8, $80^{\circ} \mathrm{C}, 120 \mathrm{~min}$ ) utilize a significantly lower concentration of acid compared to generally accepted acidic hydrolysis conditions of SIA (25-100 mM of mineral acids or $2 \mathrm{M}$ solutions of trifluoroacetic acid (TFA) and acetic acid). Additionally, widespread protocols for monosaccharide composition analysis, which require full hydrolysis of the glycan chain, use $4 \mathrm{M} \mathrm{HCl}$ or $2 \mathrm{M} \mathrm{TFA}$ at 80 $120^{\circ} \mathrm{C}$ for extended times ( 3 to $8 \mathrm{~h}$ ). Frequently, these conditions still lead to incomplete hydrolysis and destruction of the released monosaccharides. In general, the SIA glucosidic bonds is more labile under mild acidic conditions which allows their release under more gentle conditions, while the hydrolysis of other saccharides in glycan chains require harsher conditions.[10, 38] Therefore, based on the experimental absence of monosaccharides, other than SIA, and the required harsher conditions for monosaccharide release (excluding SIA), we propose that the glycan chains remain intact on AGP.

The data obtained for Neu5Ac were fitted to an exponential curve to determine rate constants. The hydrolysis in presence of PTA showed an order om magnitude rate increase when compared to $\mathrm{HCl}(11.6 \pm 0.6 \mathrm{E}-2$ min-1 vs $1.2 \pm 0.1 \mathrm{E}-2$ min -1 respectively). The rate constant for the release of Neu5Gc unfortunately could not be accurately determined most likely due to the outlier at $30 \mathrm{~min}$ observed in presence of PTA. Compared to SDS-PAGE results, the kinetic data obtained with HPAEC-PAD show a larger rate increase in terminal bond hydrolysis when using PTA, however both methods indicate that release of SIAs from AGP is completed within 60 min of incubation with PTA.

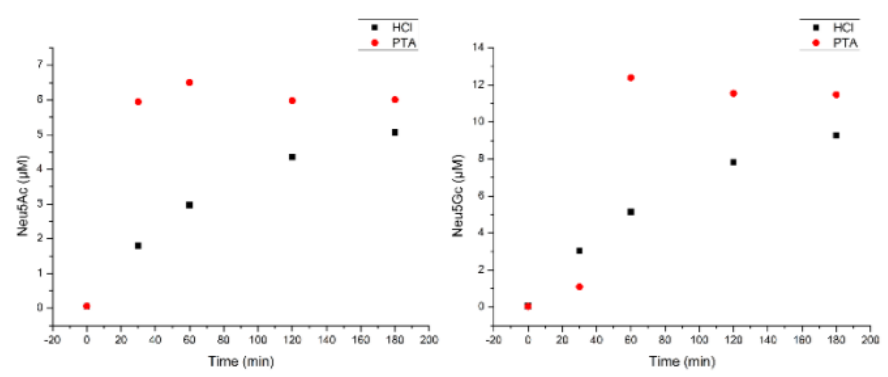

Figure 10. Amount of Neu5Ac (left) and Neu5Gc (right) released from a 0.2 $\mathrm{mg} / \mathrm{mL}$ solution of AGP incubated at $\mathrm{pH} 2.8$ and $80{ }^{\circ} \mathrm{C}$ with $\mathrm{HCl}$ and PTA measured by HPAEC-PAD.

\section{Conclusions}

A range of heteropolyacids has been shown to effectively promote fast and selective release of sialic acids from alpha 1-acid glycoprotein. SDS-PAGE and HPAEC-PAD results show that after incubation of the protein with HPAs at $80^{\circ} \mathrm{C}$ and $\mathrm{pH} 2.8$ 
complete removal of sialic acids has been achieved with no observed destruction of the protein core or the remaining glycan chains. The released sialic acid preserves an intact structure upon its excision form the protein, which makes the reported method suitable for the analysis of modifications of sialic acid structure which play an important role in numerous biological processes. The kinetics of the sialic acid release in the presence of heteropolyacids is faster than when using conventional mineral acids and therefore shorter incubation times are required which eliminate degradation of the sialic acid and the protein backbone. The degradation of sialic acid and proteins has previously been reported under similar conditions.[39] The Trp fluorescence and CD spectroscopy show that despite the negative charge of the heteropolyacids and glycoprotein, their interaction takes place in solution and is likely to occur via non-covalent binding. Such interaction between the negatively charged heteropolyanion and the glycoprotein are likely to lead to stabilization of the sialosyl cation that is formed during the glycosidic bond hydrolysis. The formation of glycosyl cation has been proposed in acid promoted glycosidic bond hydrolysis,[40] and the increased reactivity of HPAs compared to mineral acids is likely related to their ability to stabilize reaction intermediate cations, as previously proposed in hydration reactions that exhibited superior reactivity of PTA.[12, 41] Both ${ }_{1} \mathrm{H}$ NMR and HPAEC-PAD results show that no other sugars are released during the hydrolysis and that the method can be used for selective release of sialic acid from a glycoprotein. Furthermore, the described protocol is easy, fast, low-cost and results in the quantitative release of sialic acid. Therefore, the reported procedure might be applicable for monitoring the degree of protein sialylation which has a major impact on the receptor recognition, biological half-life $[7,15]$ and quality of the therapeutic proteins, that represent the most significant and fastest growing segment of the pharmaceutical market in the past decade.

\section{Experimental Section}

\section{Materials}

Phosphotungstic acid hydrate, silicotungstic acid hydrate, alpha-1-acid glycoprotein from bovine plasma (G3643), glycine for electrophoresis, tetramethyl-ethylenediamine, trifluoroacetic acid, phosphoric acid, sodium phosphate monobasic dehydrate, trichloroacetic acid and ammonium persulfate for electrophoresis were purchased form Sigma-Aldrich. Phosphomolybdic acid was purchased from Riedel-de Haën. $\mathrm{HCl}, \mathrm{H}_{2} \mathrm{SO}_{4}$, Tris(hydroxymethyl) aminomethane $99.8 \%$, isopropanol, sodium acetate, sodium metatungstate, and dodecyl sulfate sodium salt $99 \%$ were obtained from ACROS organics. Acetic acid $99-100 \%$ and acetone for HPLC was bought from VWR chemicals. Acrylamide 29:1 for molecular biology was purchased from AppliChem. Glycerol was acquired from Invitrogen. Bromophenol blue was obtained from Fluka analytical. PageRulerтм prestained protein ladder 10 to $180 \mathrm{kDa}$ was purchased from ThermoFisher Scientific. Brilliant blue G-250 was purchased from Fisher Bioreagents. All chemicals were used as bought, without purification, except for phosphotungstic and silicotungstic acid which were dried under air at $150{ }^{\circ} \mathrm{C}$ for 2 hours to obtain $\left[\left(\mathrm{H}_{3} \mathrm{PW}_{12} \mathrm{O}_{40}\right) \cdot 6 \mathrm{H}_{2} \mathrm{O}\right]$ and anhydrous silicotungstic acid. $\alpha-\mathrm{K}_{6} \mathrm{P}_{2} \mathrm{~W}_{18} \mathrm{O}_{62} \cdot 14 \mathrm{H}_{2} \mathrm{O}$ was synthesized and characterized according to literature.[42]

\section{Desialylation reaction}

A $1 \mathrm{mg} / \mathrm{ml}(23.26 \mu \mathrm{M})$ solution of AGP was prepared in water and mixed with a solution of HPA $(0.5 \mathrm{mM})$ or $\mathrm{NaWO}_{4}(6 \mathrm{mM})$ in a $1: 5$ volume ratio with final concentrations of $4.65 \mu \mathrm{M}$ AGP and $0.4 \mathrm{mM}$ HPA or $4.8 \mathrm{mM}$ $\mathrm{NaWO}_{4}$. The $\mathrm{pH}$ of the samples was adjusted to 2.8 , which is the $\mathrm{pH}$ of the AGP/PTA solution, with small quantities of $\mathrm{NaOH} / \mathrm{HCl}$. This mixture was incubated in Eppendorf tubes at $80^{\circ} \mathrm{C}$ and $1000 \mathrm{rpm}$ for $120 \mathrm{~min}$ with samples taken at regular intervals.

As the acid comparison study, AGP was incubated with phosphotungstic acid, $\mathrm{HCl}, \mathrm{H}_{2} \mathrm{SO}_{4}, \mathrm{CH}_{3} \mathrm{COOH}$ and $\mathrm{CF}_{3} \mathrm{COOH}$. All acids were diluted with water to the $\mathrm{pH}$ of a $0.5 \mathrm{mM}$ solution of phosphotungstic acid, namely 2.7 . The samples were prepared in a 1:5 volume ratio of AGP:acid and incubated at $80^{\circ} \mathrm{C}$ for $160 \mathrm{~min}$ with samples taken at regular intervals.

\section{SDS-PAGE analysis}

Samples were separated in 15\% Laemmli gels which were fixed in a 12 $\mathrm{w} / \mathrm{v} \%$ solution of trichloroacetic acid and stained in a colloidal coomassie solution overnight.[43] Destained gels were imaged with a Gel Doc EZ imager (Bio-Rad) and analysed with Image Lab software (Bio-Rad). All data were further analysed with Origin pro 8 from OriginLab.

\section{${ }_{1} \mathrm{H}-\mathrm{NMR}$ study of SIA release}

A $0.01 \mathrm{mM}$ solution of alpha-1-acid glycoprotein in $\mathrm{D}_{2} \mathrm{O}$ was prepared and a $1 \mathrm{H}$-NMR spectrum was measured at $10^{\circ} \mathrm{C}$. $10 \mu \mathrm{l}$ of a $30.5 \mathrm{mM}$ silicotungstic acid solution was added to the AGP solution to a final concentration of $0.5 \mathrm{mM}$ and the sample was measured again at $10^{\circ} \mathrm{C}$. In the next step, the sample was heated to $80^{\circ} \mathrm{C}$ and a measurement was performed every $10 \mathrm{~min}$. After $120 \mathrm{~min}$, the sample was cooled down and measured again at $10^{\circ} \mathrm{C}$. All NMR spectra were recorded with TMSP-d4 (3 mM in $\mathrm{D}_{2} \mathrm{O}, 0$ ppm) as an external reference on a Bruker Avance II 600 spectrometer.

\section{P-NMR study of glucose-6-phosphate}

A $5 \mathrm{mM}$ solution of glucose-6-phosphate in $\mathrm{D}_{2} \mathrm{O}$ was prepared, the $\mathrm{pH}$ was adjusted to 2.8 using DCl and a 31P-NMR spectrum was measured at RT. This sample was incubated at $80^{\circ} \mathrm{C}$ for $120 \mathrm{~min}$ after which it was measured again at RT. A second sample of $5 \mathrm{mM}$ glucose-6-phosphate and $0.4 \mathrm{mM}$ silicotungstic acid was prepared at $\mathrm{pH} 2.8$, which was incubated at $80^{\circ} \mathrm{C}$ for $120 \mathrm{~min}$ and a $31 \mathrm{P}-\mathrm{NMR}$ spectrum was measured at RT. All NMR spectra were recorded and corrected to $25 \% \mathrm{H}_{3} \mathrm{PO}_{4}$ (in D2O, 0 ppm) as an external reference on a Bruker Avance II 400 spectrometer.

\section{Tryptophan fluorescence quenching}

The steady state fluorescence experiments were recorded on FLS980 spectrometer from Edinburgh instruments. A $10 \mu \mathrm{M}$ AGP sample was prepared in a $10 \mathrm{mM}$ citrate buffer $(\mathrm{pH} 2.8)$ and in water. The PTA concentration in the sample was increased stepwise from 1 to $10 \mu \mathrm{M}$ in the buffer and from 1 to $12 \mu \mathrm{M}$ in water. This was done by adding $5 \mu$ of a $600 \mu \mathrm{M}$ stock solution of PTA to the $3 \mathrm{ml}$ AGP sample after each measurement and stirring during 5 minutes. The sample was measured in a quartz cuvette with an optical path length of $10.0 \mathrm{~mm}$. The emission spectra were recorded at room temperature from 300 to $450 \mathrm{~nm}$, with excitation at $295 \mathrm{~nm}$ to avoid excitation of the tyrosine residues present in the protein.

\section{CD spectroscopy}

Samples were prepared by dissolving AGP $(0.2 \mathrm{mG} / \mathrm{mL}$ ) in water (control) and in an aqueous solution of PTA $(0.08 \mathrm{mM})$. The $\mathrm{pH}$ of the samples was adjusted to 2.8. CD spectra were recorded on J-1500 CD spectrometer 
from Jasco with a Peltier heating element. The samples were measured in cuvettes with a path length of $1 \mathrm{mM}$ at $20^{\circ} \mathrm{C}$, the temperature was regulated by a Peltier element.

\section{HPAEC-PAD}

AGP $(0.2 \mathrm{mg} / \mathrm{mL})$ was incubated in a dilute $\mathrm{HCl}$ solution and an aqueous solution of PTA $(0.4 \mathrm{mM})$ at $\mathrm{pH} 2.8$ and $80^{\circ} \mathrm{C}$ for different time increments. The samples were separated on an ICS3000 system (Thermo Scientific Dionex) at $32^{\circ} \mathrm{C}$ with a flow rate of $250 \mu \mathrm{l} / \mathrm{min}$. $15 \mu \mathrm{l}$ sample volume was injected on a Guard CarboPac PA100 $(2 \times 50 \mathrm{~mm})$ in series with an analytical CarboPac PA100 (2 x $250 \mathrm{~mm})$ equilibrated for 9 min with 90 $\mathrm{mM}$ CO2-free $\mathrm{NaOH}$. Elution of the sugars happened with $90 \mathrm{mM} \mathrm{NaOH}$ with an increasing NaAc-gradient. From $\min 0$ to 6 , the $\mathrm{NaAc}$ concentration increased linearly from 0 to $10 \mathrm{mM}$; from $\min 6$ to 16 , the concentration increased linearly from 10 to $100 \mathrm{mM}$; from min 16 to 26 , the concentration increased linearly from 100 to $175 \mathrm{mM}$. $500 \mathrm{mM} \mathrm{NaAc}$ during $1 \mathrm{~min}$ was used for the regeneration of the columns and $90 \mathrm{mM} \mathrm{NaOH}$ during $9 \mathrm{~min}$ was used to equilibrate the column for the next sample. Samples were calibrated with a $20 \mu \mathrm{M}$ solution of Neu5Ac in water.

Supporting information: SDS-PAGE kinetic studies and Trp fluorescence data are given.

\section{Acknowledgements}

L.V.R. thanks KU Leuven for the financila support. T.N.P.V. is grateful to Research Foundation Flanders (Grant Nr. G0D3219N) and European Commission (Horizon 2020, FoodEnTwin project (GA No. 810752) for the funding.

\section{Author contribution}

L.V.R performed all kinetic and interaction experiments. J.A. performed SDS PAGE experiments. T.S. did the HPAEC-PAD experiments. T.P.V and W.V.E. helped with the interpretation, analysis, and writing up the data.

Keywords: Sialic acid, glycosidic bond, polyoxometalate, heteropolyacid, $\alpha$-1-acid glycoprotein, HPAEC-PAD

[1] a) F. N. Lamari and N. K. Karamanos, Journal of Chromatography B 2002 781, 3-19; b) C. Bull, M. H. den Brok and G. J. Adema, Biochim Biophys Acta 2014, 1846, 238-246.

[2] a) A. Varki and P. Gagneux, Ann N Y Acad Sci 2012, 1253, 16-36; b) P. R. Crocker, Curr. Opin. Pharmacol. 2005, 5, 431-437; c) P. R. Crocker, J. C. Paulson and A. Varki, Nat. Rev. Immunol. 2007, 7, 255-266.

[3] A. Varki, J Autoimmun 2017, 83, 134-142.

[4] A. Varki and R. Schauer in Sialic Acids, Eds.: A. Varki, R. D. Cummings, J. D. Esko, H. H. Freeze, P. Stanley, C. R. Bertozzi, G. W. Hart and M. E. Etzler), Cold Spring Harbor Laboratory Press, Cold Spring Harbor, NY USA, 2009.

[5] a) G. Walsh, Nat Biotechnol 2010, 28, 917-924; b) G. Walsh and R. Jefferis, Nature biotechnology 2006, 24, 1241-1252.

[6] R. Schauer, Glycoconj J 2000, 17, 485-499.

[7] a) A. G. Morell, G. Gregoriadis, I. H. Scheinberg, J. Hickman and G. Ashwell, J Biol Chem 1971, 246, 1461-1467; b) B. Byrne, G. G. Donohoe and R. O'Kennedy, Drug Discov Today 2007, 12, 319-326.

[8] E. Higgins, Glycoconjugate journal 2010, 27, 211-225.
[9] N. Karamanos, A. Manouras, D. Politou, P. Gritsoni and T. Tsegenidis, Comparative Biochemistry and Physiology Part B: Comparative Biochemistry 1991, 100, 827-832.

[10] N. K. Karamanos, B. Wikström, C. A. Antonopoulos and A. Hjerpe, Journal of Chromatography A 1990, 503, 421-429.

[11] a) D. L. Long, R. Tsunashima and L. Cronin, Angewandte Chemie International Edition 2010, 49, 1736-1758; b) Y.-F. Song and R. Tsunashima, Chemical Society Reviews 2012, 41, 7384-7402; c) N. I. Gumerova and A. Rompel, Nature Reviews Chemistry 2018, 2, 0112.

[12] I. V. Kozhevnikov, Chemical Reviews 1998, 98, 171-198.

[13] a) M. N. Timofeeva, Applied Catalysis A: General 2003, 256, 19-35; b) S.-S. Wang and G.-Y. Yang, Chemical Reviews 2015, 115, 4893-4962.

[14] a) Y. Izumi, K. Matsuo and K. Urabe, Journal of Molecular Catalysis 1983, 18, 299-314; b) I. V. Kozhevnikov, Applied Catalysis A: General 2003, 256, 3-18.

[15] H. Firouzabadi and A. A. Jafari, Journal of the Iranian Chemical Society 2005, 2, 85-114.

[16] J. Tian, J. Wang, S. Zhao, C. Jiang, X. Zhang and X. Wang, Cellulose 2010, 17, 587-594.

[17] a) T. K. N. Luong, P. Shestakova, T. T. Mihaylov, G. Absillis, K. Pierloot and T. N. Parac-Vogt, Chemistry - A European Journal 2015, 21, 44284439; b) K. T. Luong, G. Absillis, T. Parac-Vogt and P. Shestakova, Journal of Biological Inorganic Chemistry 2014, 19, S264-S264; c) T. Mihaylov, T. Parac-Vogt and K. Pierloot, Inorganic Chemistry 2012, 51, 9619-9628; d) P. H. Ho, E. Breynaert, C. E. A. Kirschhock and T. N. Parac-Vogt, Dalton Trans 2011, 40, 295-300; e) N. Steens, A. M. Ramadan and T. N. Parac-Vogt, Chem Commun (Camb) 2009, 965-967; f) E. Cartuyvels, G. Absillis and T. N. Parac-Vogt, Chemical Communications 2008, 85-87.

[18] a) G. Absillis and T. N. Parac-Vogt, Inorg Chem 2012, 51, 9902-9910; b) V. Goovaerts, K. Stroobants, G. Absillis and T. N. Parac-Vogt, Physical Chemistry Chemical Physics 2013, 15, 18378-18387; c) H. G. T. Ly, G. Absillis, S. R. Bajpe, J. a. Martens and T. N. Parac-Vogt, European Journal of Inorganic Chemistry 2013, 4601-4611; d) H. G. T. Ly, G. Absillis and T. N. Parac-Vogt, Dalton Transactions 2013, 42, 1092910938; e) K. Stroobants, E. Moelants, H. G. T. Ly, P. Proost, K. Bartik and T. N. Parac-Vogt, Chemistry - A European Journal 2013, 19, 2848-2858; f) A. Sap, G. Absillis and T. N. Parac-Vogt, Dalton Trans 2015, 44, 15391548; g) K. Stroobants, G. Absillis, E. Moelants, P. Proost and T. N. Parac-Vogt, Chemistry - A European Journal 2014, 20, 3894-3897; h) K. Stroobants, D. Saadallah, G. Bruylants and T. N. Parac-Vogt, Physical chemistry chemical physics : PCCP 2014, 16, 21778-21787; i) V. Goovaerts, K. Stroobants, G. Absillis and T. N. Parac-Vogt, Inorganics 2015, 3, 230-245; j) V. Goovaerts, K. Stroobants, G. Absillis and T. N. Parac-Vogt, Journal of Inorganic Biochemistry 2015; k) H. G. T. Ly, G. Absillis, R. Janssens, P. Proost and T. N. Parac-Vogt, Angewandte Chemie International Edition 2015, 54, 7391-7394; I) A. Sap, E. De Zitter, L. Van Meervelt and T. N. Parac-Vogt, Chemistry - A European Journal 2015, 21, 11692-11695; m) T. Quanten, P. Shestakova, D. Van Den Bulck, C. Kirschhock and T. N. Parac-Vogt, Chemistry - A European Journal 2016, 22, 3775-3784.

[19] L. S. Van Rompuy and T. N. Parac-Vogt, Chem Commun 2017, 53, 10600-10603.

[20] T. Fournier, N. Medjoubi-N and D. Porquet, Biochimica et Biophysica Acta (BBA) - Protein Structure and Molecular Enzymology 2000, 1482, 157-171.

[21] Z. Luo, H. Lei, Y. Sun, X. Liu and D.-F. Su, Journal of Physiology and Biochemistry 2015, 71, 329-340.

[22] M. Nakano, K. Kakehi, M.-H. Tsai and Y. C. Lee, Glycobiology 2004, 14, $431-441$.

[23] a) B. J. Smith and V. A. Patrick, Australian Journal of Chemistry 2002, 55, 281-286; b) B. J. Smith and V. A. Patrick, Australian Journal of Chemistry 2000, 53, 965-965.

[24] B. J. Smith and V. A. Patrick, Australian Journal of Chemistry 2004, 57, 261-261.

[25] G. B. McGarvey and J. B. Moffat, Journal of Molecular Catalysis 1991, $69,137-155$. 
[26] J. Yijia, N.-S. Yasser, L. Cynthia, L. Wei, P. Joey, M. David, W. Zai-Qing, F. Kiyoshi, P. Monica, D. Lisa, C. Grace, T. Gianni, V. Aylin, M.-S. Tony, F. Erwin, D. Janice and N. Linda, Journal of Pharmaceutical Sciences 2009, 98, 4695-4710.

[27] M. Nakano, K. Kakehi, M.-H. Tsai and Y. C. Lee, Glycobiology 2004, 14, 431-441.

[28] A. W. Barb, J. N. Glushka and J. H. Prestegard, Journal of chemical education 2011, 88, 95-97.

[29] A. L. Skinner and J. S. Laurence, Journal of pharmaceutical sciences 2008, 97, 4670-4695.

[30] J. Haverkamp, H. van Halbeek, L. Dorland, J. F. Vliegenthart, R. Pfeil and R. Schauer, Eur J Biochem 1982, 122, 305-311.

[31] L. S. Van Rompuy and T. N. Parac-Vogt, Current opinion in biotechnology 2019, 58, 92-99.

[32] a) D. C. Crans, I. Sanchez-Lombardo and C. C. McLauchlan, Front Chem 2019, 7, 462; b) A. Bashan and A. Yonath, J Mol Struct 2008, 890, 289294.

[33] a) The UniProt Consortium, Nucleic Acids Research 2017, 45, D158D169; b) D. L. Schonfeld, R. B. Ravelli, U. Mueller and A. Skerra, J Mol Biol 2008, 384, 393-405.

[34] a) K. Stroobants, V. Goovaerts, G. Absillis, G. Bruylants, E. Moelants, P. Proost and T. N. Parac-Vogt, Chemistry - A European Journal 2014, 20 , 9567-9577; b) V. Goovaerts, K. Stroobants, G. Absillis and T. N. ParacVogt, J Inorg Biochem 2015, 150, 72-80.

[35] C. Louis-Jeune, M. A. Andrade-Navarro and C. Perez-Iratxeta, Proteins 2012, 80, 374-381.

[36] J. S. Rohrer, L. Basumallick and D. Hurum, Biochemistry (Mosc) 2013 78, 697-709.

[37] L. Silverman and D. Glick, J Cell Biol 1969, 40, 761-767.

[38] a) E. Higgins, Glycoconjugate journal 2010, 27, 211-225; b) L. Zhang, S. Luo and B. Zhang, mAbs 2015, 8, 205-215.

[39] a) A. Li, R. C. Sowder, L. E. Henderson, S. P. Moore, D. J. Garfinkel and R. J. Fisher, Anal Chem 2001, 73, 5395-5402; b) C. J. Shaw, H. Chao and B. Xiao, Journal of Chromatography A 2001, 365-370; c) J. Schultz, H. Allison and M. Grice, Biochemistry 1962, 1, 694-698.

[40] J. J. Ziarek, F. C. Peterson, B. L. Lytle and B. F. Volkman in Binding site identification and structure determination of protein-ligand complexes by NMR: A semiautomated approach, Vol. 493 Elsevier, 2011, pp. 241-275.

[41] K. Urabe, K. Futsita and Y. Izumi, Shokubai 1980, 22, 223-225.

[42] R. Contant, G. Klemperer Walter and O. Yaghi in Early Transition Metal Polyoxoanions, (Ed. A. P. Ginsberg), John Wiley \& Sons, Inc., New York, USA, 1990.

[43] a) D. W. Cleveland, S. G. Fischer, M. W. Kirschner and U. K. Laemmli, Journal of Biological Chemistry 1977, 252, 1102-1106; b) G. Candiano M. Bruschi, L. Musante, L. Santucci, G. M. Ghiggeri, B. Carnemolla, P. Orecchia, L. Zardi and P. G. Righetti, ELECTROPHORESIS 2004, 25, 1327-1333. 


\section{Entry for the Table of Contents}

Layout 1:

\section{FULL PAPER}

A range of Keggin and Wells-Dawson type heteropolyacids have been shown to selectively hydrolyze terminal glycosidic bond in heavily glycosylated $\alpha-1$-acid glycoprotein, resulting in the removal of sialic acids with no observed destruction of the protein core or the residual glycan chains.
Laura Sofia Van Rompuy, Jens Moons, Jo Aelbers, Tom Stryf, Wim Van Den Ende and Tatjana N. Parac-Vogt*

\section{Page No. - Page No.}

Selective hydrolysis of terminal glycosidic bond from $\alpha-1$-acid glycoprotein promoted by Keggin and Wells-Dawson type heteropolyacids 
WILEY-VCH

FULL PAPER 